\title{
Towards a Better Kurdish Language
}

\author{
Ibrahim A. Murad \\ University of Garmian-College of Education-English Department
}

\begin{abstract}
Language is the identity of the nations and one of the most significant elements in its continuity and survival. For this reason, it is taken for the greatest interest by every nation that wants to run the risks of its dying out. This interest takes various ways and methods that are targeted at keeping language alive and active. Among these is the process of composing dictionaries that embrace the basic unit of language i.e. words.

The present study is an attempt at scrutinizing the English and Kurdish languages from the 'dictionary aspect' of both languages through a comparative study. It shows how the English is served in the best way through this process and how all the words in English are kept save from the danger of dissolution. It also shows that these attempts are responsible for the wide spread of English all over the world and they encourage the non-native speakers to learn it as easily as possible.

Against these attempts, the study shows that the Kurdish language is almost neglected and no great attention is paid to it. It reached the conclusion that the academic centers like the universities are mainly responsible for this negligence since they pay greater attention to things that are of less importance.
\end{abstract}

Key words: language, interest, process, English, Kurdish, attempt.

\section{Language and dictionary}

Language is the machine that operates the nations and keeps their existence alive and the only aspect that, if annihilated, the result will be a sure death for the entity to which it belongs. Keeping language strong and active; therefore, is an essential task of all the nations and peoples. One of the critical methods for that purpose is, undoubtedly, achieved through well-arranged and worked dictionaries. That is the reason why a widely famed dictionary like Merriam-Webster's Collegiate 
Dictionary defines the word dictionary as "a reference source in print or electronic form containing words usu. alphabetically arranged along with information about their forms, pronunciations, functions, etymologies, meanings, and syntactical and idiomatic uses" (347). The definition shows how important is a dictionary for any given language. It is this fact that urged and urges different nations and communities to pay greater interest to composing dictionaries for their languages, believing that it is a significant national task. That is the same reason that encouraged two communities in this respect who "have recently taken a significant step towards the same goal: creating a dictionary for their language. Kaansa speakers in Burkina Faso and Malango speakers in the Solomon Islands recently completed a Rapid Word Collection workshop" (https://www.sil.org). This process started not without the support of the political powers of the said communities. In Burkina Faso, for instance, the king himself supported and participated in the project and this is how consultant Kevin Warfel appreciates that support:

The king not only supported the workshop in principle, but also spoke passionately to the entire group of participants on the first day about the importance of collecting Kaansa words and of publishing a dictionary, and then he himself took part as a language expert as much as possible during the word-collection phase. His example, together with the hierarchical structure of the society, went far in motivating the participants to invest themselves significantly in the work. Without such support from the king, the results of the workshop might have been quite different (Ibid).

This interest in the significant role of dictionaries in the survival and development of languages is responsible, in one way or another, for the long history of the efforts made by men of letters in different nations in the world towards the attainment of this national duty and accomplishment. 


\section{The Debuts}

Being one of the most developed nations in Europe and the world after the Greeks and the Romans; it is of little surprise that the English language drew the attention of a large number of men of letters to pay greater attention to its rules, regulations, and the multiple meanings of each word in it. The British library, an organization that was initiated in the seventieth of the last century follows those attempts close and as Mark Damian Ament and Tatiana Napoli note in their comprehensive article "The History of English Dictionaries" " there you can learn that the first initial attempt at production of an English dictionary came in 1582, with Mulcaster's Elementarie, an 8,000 word list (with no definitions, albeit), in an attempt to start organizing the English language"(1). The first English dictionary accordingly can be traced back as old as the Middle Ages or somehow later. But the first real English dictionary, according to Jack Lynch, is Cawdrey's Table Alphabetical (of 1604) (Ibid).

Cawdrey (ca. 1538 - after 1604), who was a school teacher, provided a short definition for each one of the 2543 headwords of the dictionary that covered 130 pages and, more interestingly, he marked origins of the words that were borrowed into English from other languages. In the beginning he refers to the letters alphabetically in the following way:

$\begin{array}{cl}\circ & \underline{\mathrm{A}} \\ \circ & \underline{\mathrm{B}} \\ \circ & \underline{\mathrm{D}} \\ \circ & \underline{\mathrm{E}} \\ \circ & \underline{\mathrm{F}} \\ \circ & \underline{\mathrm{G}} \\ \circ & \underline{\mathrm{H}} \\ \circ & \underline{\mathrm{I}}\end{array}$

- No Words Beginning With J

- No Words Beginning With K

$$
\circ \underline{\underline{L}}
$$




$\begin{array}{ll}\circ & \underline{\mathrm{N}} \\ \circ & \underline{\mathrm{O}} \\ \circ & \underline{\mathrm{P}} \\ \circ & \underline{\mathrm{R}} \\ \circ & \underline{\mathrm{S}} \\ \circ & \underline{\mathrm{T}}\end{array}$

- No Words Beginning With U: See $\underline{\mathrm{V}}$

○ $\underline{V}$

- No Words Beginning With W

- No Words Beginning With X

- No Words Beginning With Y

$\circ \underline{Z}$

(Siemens: 2).

The alphabetical order of the entries shows that he compiler followed the true path of writing a dictionary that is still followed, although the range of his attempt is clearly limited. It is strange that Cawdrey did not find any words in the English language of that day starting with the letters $\mathrm{j}, \mathrm{k}, \mathrm{v}, \mathrm{w}, \mathrm{x}, \mathrm{y}$ ).

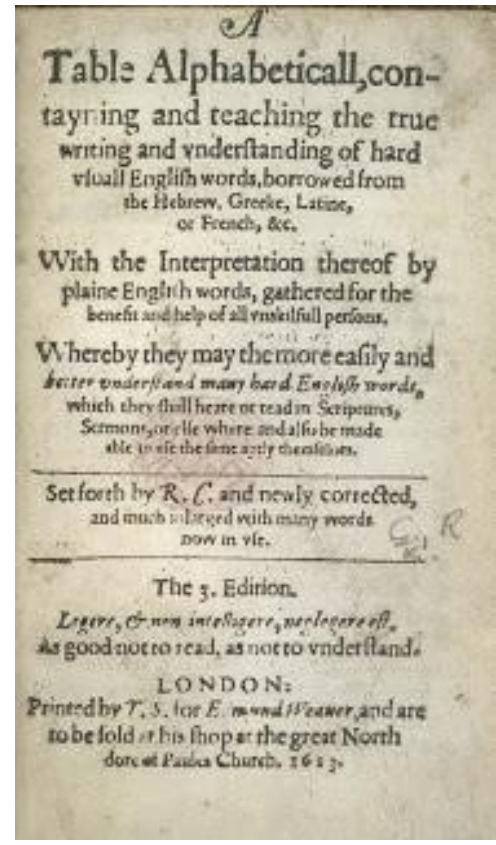

The title page to the "Table Alphabeticall"

This first attempt seems, as its subtitle indicates, to have been directed to a specific purpose and specified end, Cawdrey subtitled his dictionary "for the 
benefit of Ladies, Gentlewomen, and other unskilled folk": his aim was to create an in-depth guide for the lesser educated who might not know the "hard usual English words, borrowed from the Hebrew, Greeke, Latine, or French" (Ament \& Napoli:3)

Although just a beginning and quite an insufficient source for the English language with all its defects; yet it drew the attention of the intelligentsia and received its deserved care:

For instance, the Table was published in a new edition by the Bodleian Library, from the University of Oxford, in 2007). And Raymond G. Siemens, from the Department of English at University of British Columbia, edited an online version of Cawdrey's Table, with a transcription of the 1604 edition. It is possible to find it at the University of Toronto Library's site:http://www.library.utoronto.ca/utel/ret/cawdrey/cawdrey0.ht ml (Ibid).

The most obvious opposition and accusation for that effort was based on the fact that Cawdrey depended upon three other sources to compile his work; a step considered by the majority of the intelligentsia as mere plagiarism: First: Cooke's work of 1596 from which he took his outline and something like $87 \%$ of the contents. Second: A medical work by Oswald Gabelkhouer, translated from Latin to English by a Dutchman called A.M. Third: An English Expository by John Bullokar which was printed in 1618 and included many archaic words. This work had 14 editions after it was printed for the first time (Read: 6-9).

But the seeds of the first and most known English dictionary in the history of England were put when " Humphrey Wanley set down a list of 'good books wanted' which he hoped the society of Antiquaries would undertake" (Ibid). It seems that only the famous poet and critic, Samuel Johnson, known as Dr. Johnson as well could tackle such a complicated duty and achieve it in only nine years. The 
dictionary which was first published in 1755 remains one of the most known and accomplished names when it comes to studying the history of the English dictionary. Although he was helped by a number of friends; yet, he was the major power behind the project. He started reading from the English literature up to his time and collecting central words and expressions in the English language. It includes about 43,500 words but they were much better selected than the 663 dictionaries before it. Johnson defined each word I a great detail (for the first time up to then). That is not all, as some critics remark ;

Johnson's dictionary was the first one to make an effort to standardize the spelling of the words, illustrating the meanings by literary quotation of authors like Shakespeare, Milton and Dryden. In addition, Johnson added notes on a word's usage rather than being simply descriptive, like Cawdrey. But perhaps the main reason for Johnson's everlasting fame is the fact that, while everybody was busy trying to enlist exclusively the "hard words", Johnson opened his pages to words people actually used (Ament and Napoli: 4).

This step of going beyond only the difficult words (followed in the dictionaries before him) is certainly the reason for regarding it the most influential work in this field and in the mono-lingual dictionary in the English language. 
OA'tMFAL. $n$. f: [oat and meal.] Flower made by grinding oats.

Oatmeal and butter, outwardly applied, dry the fcab on the head. Arbutbnot on Aliment.

Our neighbours tell me oft, in joking talk,

Of afhes, leather, oatmeal, bran, and chalk.

OA'tMeAL. $n: f$. An herb.

Gay.

OAтs. n. f. [azen, Saxon.] A grain, which in England is generally given to horfes, but in Scotland fupports the people.

It is of the grafs leaved tribe; the flowers have no petals, and are difpofed in a loofe panicle : the grain is eatable. The meal nakes tolerable good bread.

Miller. The oats have eaten the horfes. Shakefpeare.

It is bare mechanifm, no otherwife produced than the turning of a wild oatbeard, by the infinuation of the particles of moifture.

For your lean cattle, fodder them with barley ftraw firft, and the oat ftraw laft. Mortimer's Hußbandry.

His horfe's allowance of oats and beans, was greater than the journey required.

OA'tтhIstre. n. $\int$. [oat and thifle.] An herb.

Swift.

\section{(www.google.iq)}

The history of the Kurdish dictionary is by no means comparable to its English counterpart as far as time and antiquity are concerned; yet, it seems that both moved on parallel lines in respect to their historical developments. Due to the influence of the foreigners upon the Kurdish intelligentsia and people as well, a large number of dictionaries were compiled by Kurds and foreigners as well like: Arabic-Kurdish, Kurdish-Arabic, Italian-Kurdish, Kurdish- Russian, RussianKurdish, Kurdish-French, Kurdish- German, ect. This long series started with "'Nawbahar' by Ahmadi Khani in 1904, which is the oldest Kurdish dictionary ever written" (Haji Marif: 7).

But the first seeds of the Kurdish dictionary go as far back as 1795 when the clergyman Muhammad Mustafa (1753-1841) compiled a pamphlet of only 75 pages and a 15 pages index in which he mentions Arabic words with their Kurdish counterparts through lines of simple verse. The purpose, it is clear, was to teach the Kurdish readers, among them his students, some of the necessary Arabic word. 
Nerveless, the Kurds did not have their first Kurdish-Kurdish dictionary until 1960 when Muhammad Khal (1904 -1989) compiled the first volume of his Khal Dictionary and followed it by "the second and third volumes in 1965 and 1976 respectably" (Borakayee: 812). About the idea of writing it, the editor of the dictionary says:

Because he thought that a dictionary for the Kurdish language that includes its different dialects is important to preserve and develop the Kurdish language, the write thought of compiling one. He did not have any necessities at hand for that purpose, but he insisted on the idea and started work in 1935. It took him 41 years to finish that project in full (Khal:7).

The dictionary contains 50000 words (more than the words in Johnson's) that covers 550 B5 pages preceded by a 14 pages introduction about the origin and the rules of the Kurdish language. The writer mentions at the end of some words, the dialect to which they belong; but he does not refer to the parts of speech of the entries, and this can be regarded as one of the major defects and shortcomings of the work. Moreover, many words are recorded there, while their counterparts or close neighbours are not seen.

This work was the result of nearly thirty years of hard work and effort of the writer who had no source at hand to help him; rather he collected the words throughout that period from the people whom he met in different parts of Kurdistan and the places that he visited. So, the work is really an original one for which the writer should be acclaimed. In this respect, he seems to have done harder work than Johnson who collected most of his works from the literary works that he read and the quotations that he made. 
The second huge project for the Kurdish dictionary was simply entitled Kurdish Dictionary. It was compiled by the Kurdish poet Jgar Khwen (1903 1984) and covers 542 B4 pages. The writer, in most cases, provides synonyms for the key words with explanations and examples where necessary or where he could. The problem in this work, as in its predecessor, is that the writer focusses on one dialect among the different Kurdish dialects; the northern Kurdish (northern Kirmanji) in this case. This, undoubtedly, decreases the benefit of the dictionary for the speakers of the other dialects.

\section{Developments}

Dr. Johnson's dictionary was the first attempt at bringing dictionary to the edges of the real standard language and made him the star of the English language who is remembered and appraised for this work more than any poem or piece of literature that he wrote. By then, the situation became ready for an overall attempt to collect all the words of the language that people needed and used in their everyday life and activities.

In 1857, the Philological Society of London expressed its dissatisfaction at the situation of the English dictionaries until then, and so an "unregistered Words Committee" was formed to search for unlisted and undefined words, those lacking in current dictionaries" (Ament and Napoli: 9). The project was launched by a group of learned men headed by one Richard Chenevix Trench who was " Dean of Westminster" (Ibid). This man prepared a paper about the situation of the English dictionaries until then and identified some shortcomings that they needed to work upon. These, as Ament and Napoli said included the following points: 
- Incomplete coverage of obsolete words

- Inconsistent coverage of families of related words

- Incorrect dates for earliest use of words

- History of obsolete senses of words often omitted

- Inadequate distinction among synonyms

- Insufficient use of good illustrative quotations

- Space wasted on inappropriate or redundant content (Ibid:10).

It is interesting to mention that the Oxford University Press was the first and only establishment that agreed in 1884 to print and publish this huge project that was composed of "twenty ponderous volumes long, with 615,000 entries; 2,412,000 supporting quotations, and 60,000,000 words" (Ibid). And up today that press, supervised by academics and intelligentsia, is the most active publishing press that serves the English language and its culture and the result is a very large number of books on top of which dictionaries for the readers and learners of the most widely spoken language in th world.

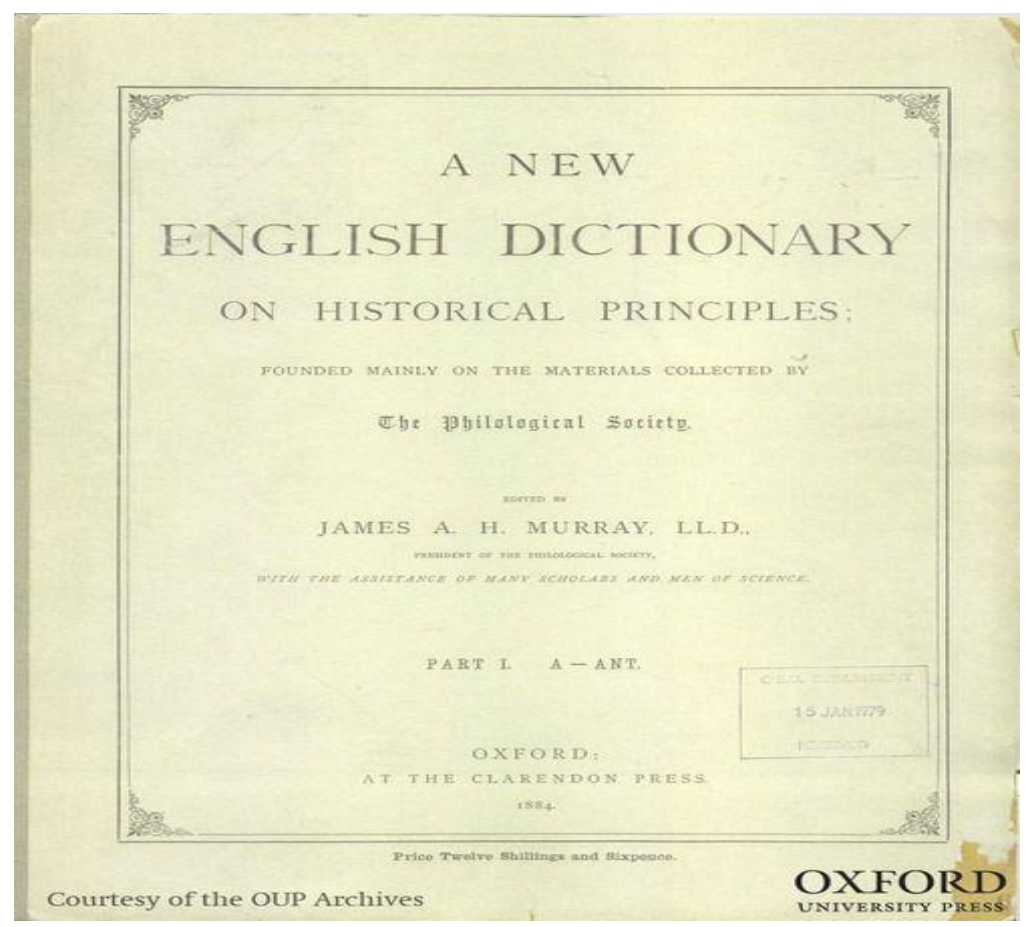


The Kurdish dictionary, like dictionaries of all the other nations, followed its path forward despite the complicated political and cultural situation in all the four parts of Kurdistan and especially southern Kurdistan which was and still is the main center of the majority of the efforts exerted for the benefit and service of the Kurish language.The Kurdish famous poet, Ahmadi Khani (1650 -1707) first tried to serve his language in this method, and he wrote a book of poems for the students to learn words from their language by putting such words against Arabic counterparts. This attempt was repeated by Sheikh Ma'aruf (1755-1843) who mentioned within 75 pages of a pamphlet hundreds of Arabic words that Kurdish students needed with their counterparts in Kurdish.

In the seventies and eighties of the last century, a number of new efforts were achieved to serve, through dictionaries, the Kurdish language even more.

The attempts; however, were concentrated upon bi-lingual dictionaries ranging among Kurdish, the mother tongue, and the neighboring languages of Arabic, Persian, Turkish, Russian, ect. In 1961, for instance, Geo Mukuriani (19031977) compiled a three thousand words Kurdish - Arabic dictionary for students that he called Mahabad. He starts the dictionary with a twenty pages introduction where he focuses upon the importance of languages for the persistence and permanence of nations. In this introduction, he mentions that he compiled a Kurdish-Kurdish dictionary that he called Kurdistan which was composed of four volumes and (45 000) words and (1300) illustrating pictures, but, unfortunately it was not printed (2). He also wrote the Arabic-Kurdish dictionary, Al-Murshid and published it in 1951 within 400 pages and followed it in 1955 by the Kurdish-Persian Kolka Zerina . 


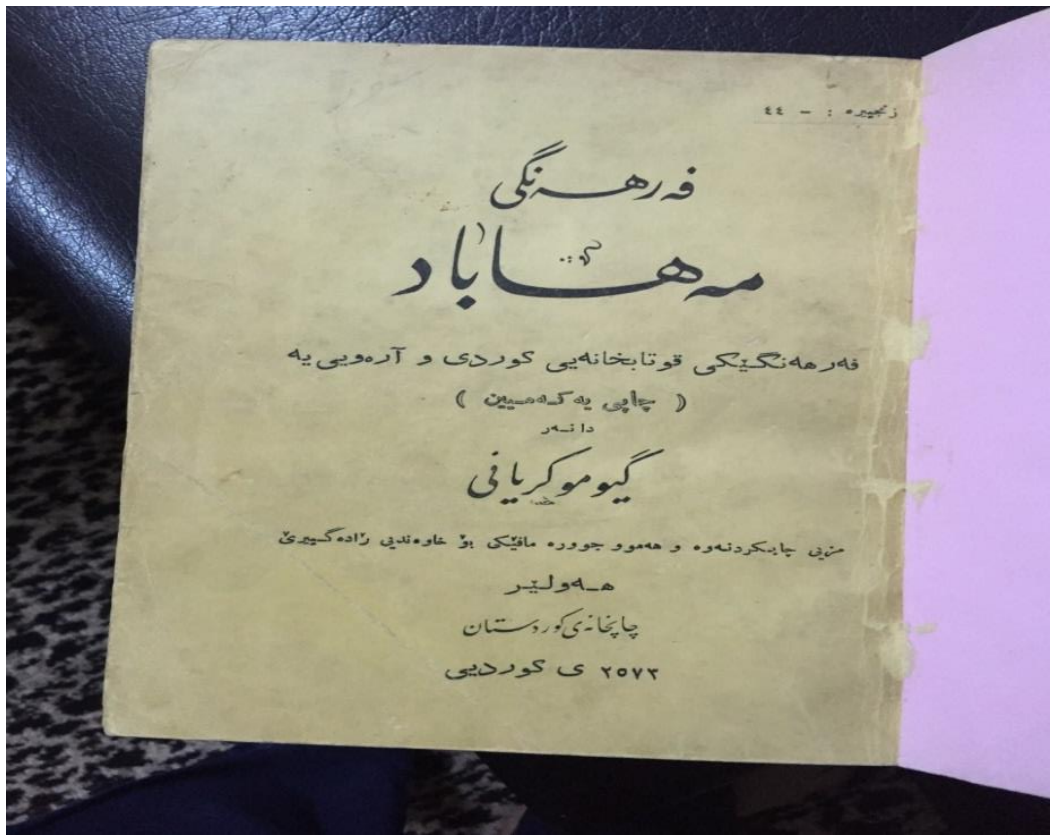

\section{To the Present}

The English language has,now, a wealth of different kinds and different duties dictionaries that cover almost all the English language spoken within the Englishspeaking countries and all over the world as well. As mentioned earlier, the Oxford University Press was the first academic establishment to support the efforts exerted to serve the English language through the lens of dictionaries since it agreed to print and publish the first English dictionary that thousands of intelligentsia and volunteers participated in collecting its words. Although the original plan for the work, it seems, was to be published in four volumes; "in April, 1928, the last volume was published. Instead of 6,400 pages in four volumes, the Dictionary published under the imposing name A New English Dictionary on Historical Principles - contained over 400,000 words and phrases in ten volumes" (http://public.oed.com/history-of-the-oed). 
It is notable to realize that such a huge academic and learning project was launched by that university press "At no period in its history has the Oxford English Dictionary been profitable commercially for Oxford University Press. However, the Press remains committed to sustaining research into the origins and development of the English language wherever it is spoken" (Ibid). In this way, the English universities especially Oxford and Cambridge served and still serve their language in the best way and nowadays, thousands of English dictionaries of diferent kinds and techniques are issued by their presses which is the oldest one in the world, started in 1480 and the second largest one after Cambridge's press.

The second significant support to the English language and culture came from the Cambridge university press, the largest in the world and the second oldest that started work in 1534. These two presses along with the presses of a large number of universities worldwide serve the English culture and language and participate actively in promoting that language and keeping it alive. Their activities in this respect, led by professors and experts in different parts of the English-speaking world, are non-stop and almost every year they come up with interesting dictionaries and useful books for the English language and literatue,

As for the Kurdish language, the story is completely different from every aspect. Excluding the Khal Dictionary (1961), the Kurdish language was not served through full Kurdish-Kurdish dictionaries except for two personal attempts.

The first one was done by the Kurdish poet, Hazhar Mukuriani who spents long years in collecting words from different parts of Kurdistan and was able, at last, to use those words to compile his Hambana Borina dictionary which was published in the Iranian capital, Tehran in 1990. About the idea behind and the chance of composing it, he writes in the introduction of the book: 
After the crisis that the Kurdish revolution faced in 1975, I went back to Iran to live with my family in a critical situation that forced me to look for any work. I came across a publishing house in Tehran and told him that I want to write a Kurdish dictionary. He asked me to translate two books to him into Persian, so that he can allow me write and publish a Kurdish dictionary; and reluctantly, I agreed. This is how I could do this small favour to my language (28-9).

The dictionary covers 1035 pages of Kurdish words in front of which there are Kurdish synonyms followed by a Persian equavelant. In some cases explanations are provided for the words instead of synonyms. It is a valuable attempt per se and every reader of the book is, without any doubt, grateful for the huge effort exerted by the writer to achieve this goal despite the unfavourable situation under which it was composed and published. Yet, it is not void of some serious shortcomings; the concentration for instance, is upon one Kurdish dialect, southern, and the other dialects are almost neglected. Furthermore, the writer did not provide the words with keys of their functions; whether they are verbs, nouns, adjectives, ect. And hardly illustrating examples are given. Despite all these facts; the dictionary fills a huge gap in the Kurdish language and it still is one of the major valuable sources for the Kurdish intelligentsia and people who work in the Kurdish language and literature.

The second Kurdish-Kurdish dictionary to appear is Geo Mukuriani's Kurdistan which was published by Aras press posthumously in 1999 after a long period of writing and composing it. Unlike its predecessors, it starts with a short introduction followed by a list of acronyms. The work that covers 940 pages, is a useful source for the Kurdish language and the writer tried his best, not with lots of shortcomings, to cover the words of all the dialects of the language. Nonetheless, it repeated most of the shortcomings of the dictionaries that 
appeared before it. The most obvious one of such shortcomings is the lack of references to the parts of the speech to which the words belong.

There is even rumour about a possible connection between this dictionary and Hambana Borina since, it is said that the draft of Kurdistan was in the Kurdish academy for a long time waiting to be published and that Hazhar was a member there; so, possibly he made use of that draft to compose his own dictionary, especially that Hazhar did not have any idea of writing a dictionary and so, the appearance of Hambana Borina was a surprise. Whether or not it is true, the two works remain valuable for the Kurdish language because so far, there is no any work that can compete with them.

The last Kurdish-Kurdish dictionary so far is, again, a personal effort by a Kurdish man of letters from Eastern Kurdistan called Abbas Jaleelian who composed his Bashoor Dictionary and published it in 2006. He followed almost exactly Mukriani's example in choosing one dialect for his focus and repeating his predecessor's shortcomings. The book covers 810 pages and takes the southern Kurdish dialect as its base.

It is interesting to realize that despite the relative freedom for the Kurdish language in, at least, southern Kurdistan since 1970 and a complete freedom for the language and its people since 1991; yet no serious attempts were done to develop this language especially in the field of the study under discussion here, i.e. Kurdish dictionary. This happens at a time when Kurdistan in general and southern Kurdistan in particular developed greatly in the academic field and nowadays we have a large number of universities and a much larger number of doctors and proffesors who are specialized in the Kurdish language and literature. 


\section{Conclusions and Recommendations}

This short comparative study came out with a number of conclusions and recommendation the most important ones of them are the followings:

\section{Conclusions}

1. The history of composing dictionaries in both the English and Kurdish languages seem to resemble each other, especially the first steps of the process.

2. The idea of plagiarism that were refered to in some stages of writing English dictionaries, can also be felt in its Kurdish counterpart as mentioned earlier.

3. The first English dictionary, refered to in this paper, is hardly a dictionary in the proper meaning of that word; the same story is also true to the Kurdish ones, some of which are mentioned here.

4. None of the first efforts for writing English dictionaries were achieved by academic people; rather men of letters were pioneers in this respect. The story is completely analogous for the first Kurdish dictionaries.

5. While the Philological Society of London formed, in 1857, a committee of experts to collect the unlisted words to be included in the English dictionary; such an idea did not come to any Kurdish society in this respect, though there is an establishment like that which is called The Kurdish Academia.

6. The University presses, especially Oxford and Cambridge presses, play vital roles in sustainability and development of the English languages by publishing, among other books, tens of dictionaries every year that serve different aspects of the English language; but the Kurdish universities re altogether absent in this respect; some because they do not presses at all.

7. English-speaking doctors and proffesors try their best non-stop in every aspect related to the English language, including in composing dictionaries; while their Kurdish counterparts can be seen nowhere in this respect and 
their activities trespass no more than holding some seminars, workshops, or conferences about their language.

8. In countries called Third World countries, like Borkina Faso and Solomon Islands committees are recently formed to collect words of theuir languages as part of a project of composing an overall dictionaries. The committees are supported by hundreds of volunteers including the king of Borkina Faso; but in Kurdistan, this important side did not receive the least attention by the government and its ministries and establishments including even the universities and its professionals.

\section{Recommendations}

The paper recommends that:

1. The government, through its specialized ministries like ministry of culture, is supposed to try to encourage the process of developing the Kurdish language through working in the field of dictionaries in the way it is done in other countries and mentioned here.

2. The Kurdish academy should found an overall committee to include specialists in the different dialects of the language to come up with a comprehensive Kurdish-Kurdish dictionary.

3. The universities in Kurdistan should try especially through the Kurdish departments and its doctors and proffesors in the same direction. 


\section{Works Cited}

- Ament, Mark Damian \& Napoli, Tatiana. "The History of English Dictionaries" http://engdictionaries.blogspot.com/ 24-3-2017

- Borakayee, Sidiq. History of Kurdish Literature, Vol 2. Erbil: Aras Publishing Press. 2008. Print.

- Haji Ma'aruf, Abdul-Rahman. About Writing Kurdish Dictionaries. Baghdad:

Al- Zaman Printing Press. 1987. Print.

- Jaleelian, Abbas. Bashoor Dictionary. Tehran: Pressman Publishing. 2006. Print.

- Khal, Muhammad. Khal Dictionary. Erbil: Aras Printing Press. 2005. Print.

- Khwen, Jgar. Kurdish Dictionary. Baghdad: Ershad Printing Press. 1962. Print.

-Mish, Frederick C. Marriam- Webster's Collegiate Dictionary. 11th Edition. Massachusetts:

Mariam-Webster, Incorporated. 2004. Print.

- Muhammad, Mahmood A. (ed) Ahmadi Book. Suleimani: Aram Publishing Press. 2010. Print.

-Mukuriani, Geo. Mahabad Dictionary. Erbil: Kurdistan Publishing Press. 1961. Print. Kolka Zerina. Erbil: Erbil Publishing Press. 1966. Print.

- .......... Al-Murshid. Erbil: Kurdistan Publishing Press. 1950. Print.

- .......... Kurdistan. Erbil: Aras Printing Press. 1999. print

- Mukuriani, Hazhar. Hambana Borina. Tehran: Sroosh Publishing. 1990. Print.

- Mulcaster, Richard. Mulcaster's "Elementarie". np. North American Reading Program Oxford English Dictionary. 1994. Web.

- Read, Allen Walker. "Dictionary". https://www.britannica.com/topic/dictionary/Majordictionaries. 2016. Accessed 22-3-2017

- Siemens, Raymond G. (ed). Robert Cawdrey's A Table Alphabetical (1604).

Renaissance Electronic Texts. Torento: Web Development Group. 1997. Web.

-https://www.sil.org/about/news/communities-pursue-language-development-through-dictionary-workshops 23-3-2017

- http://public.oed.com/history-of-the-oed/ 28-4-2017 